\title{
Free-operant (Sidman) avoidance in reciprocally cross-fostered wild and domesticated rats
}

\author{
ROBERT W. POWELL* \\ University of South Florida, Tampa, Fla. 33620
}

The offspring of field-trapped black rats and domesticated albino rats were reciprocally cross-fostered with a survival rate through weaning of $100 \%$. When the rats were studied under free-operant (Sidman) avoidance at maturity, the performance of the albino rats was superior to that of the black rats at the same shock intensities. All of the rats learned to avoid, and the performance of the black rats was the most successful that has been reported under this procedure. Conspecific-raised rats of each species were superior to foster-raised conspecifics. As a whole, the conspecific-raised group was superior to the foster-raised group. This finding suggests that black rat and albino rat mothers behaved differentially toward their foster pups to the extent that performance was subsequently impaired in a complex learning situation. The albino rats received a higher percentage of shocks early in the session (warm-up) than the black rats, and foster rearing did not seem to affect this phenomenon.

Domesticated rodents generally learn to avoid more effectively than wild rodents (Powell \& Morris, 1968; Powell, 1969; Boice, 1970), but a recent experiment found that wild cotton rats and black rats, which were born and raised in the laboratory, performed at the same asymptotic level under free-operant avoidance as albino rats (Powell, 1971). The laboratory-raised wild rats also had lower shock rates than field-raised conspecifics. However, the following differences existed between groups: (1) The field-raised and laboratory-raised wild rats required more intense electric shocks and more extended training to achieve optimum avoidance than the domesticated rats; (2) both groups of wild rats displayed greater session-to-session variability in shock rates than the albino rats.

Thus, it appears that avoidance in wild rats improves, becoming similar to domesticated rats as the life histories of the species become more similar. Laboratory rearing permits lifelong adaptation to this environment, as opposed to briefer adaptation periods which occur with field-trapped animals.

The present experiment was conducted to assess the possible effect of the mother-infant relationship upon later avoidance behavior in the offspring. This topic was studied because of the demonstrated influence of mother-infant relations upon adult emotionality

*A version of this paper was presented at the 1971 convention of the American Psychological Association, Washington, D.C. The author thanks S. A. Barnett and R. C. LaBarba for their comments on the manuscript. Requests for reprints should be sent to Robert W. Powell, Department of Psychology, University of South Florida, Tampa, Florida $\mathbf{3 3 6 2 0}$.
(Ressler, 1962; Denenberg, Ottinger, \& Stephens, 1962; LaBarba, 1967) and the reliance upon emotionality as a theoretical basis for avoidance learning (Mowrer \& Lamoreaux, 1946). Reciprocal cross-fostering, which involves the fostering of one species upon another at birth, was used to assess the influence of this variable.

\section{METHOD \\ Subjects}

Eleven albino rats and seven black rats were used. The black rats were first-generation offspring of field-trapped animals. Black rats (Rattus rattus) are members of the family Muridae (old world rats and mice), which also includes the Norway rat (Rattus norvegicus). The latter animal is the ancestor of all current domestic albino rat strains (Barnett, 1963). The rats were 6-9 months old at the start of the experiment.

\section{Apparatus}

A standard single-lever operant conditioning test chamber was used. Electric shock from a Grason-Stadler shock source (Model E1046GS) was scrambled to the grid floor of the test chamber.

\section{Cross-Fostering}

Procedure

This procedure was carried out with two litters each of albino and black rats between 24 and $72 \mathrm{~h}$ after birth. Approximately half of each litter was switched between mothers. All of the pups survived and were weaned after 30 days. They were housed in individual cages prior to and during the experiment, with free access to water and Purina Lab Chow. The composition of the experimental groups and other pertinent information is given in Table 1, which shows that the albino rats were generally larger than the black rats, males of both species were larger than females, and foster-raised rats of both species were heavier than conspecific-raised rats.

\section{Avoidance}

A free-operant avoidance procedure (Sidman, 1953) with shock-shock (S-S) and response shock (R-S) intervals of 5 and $20 \mathrm{sec}$, respectively, was used. The shock duration was $0.5 \mathrm{sec}$. Responses in the presence of shock did not terminate it. Experimental sessions were $2 \mathrm{~h}$ per day.

All rats were studied under shock intensities of 1.5, 2.5, 3.5, and $5.0 \mathrm{~mA}$ in succession. Then all rats except RA-5, -7 , and -8 were studied as shock intensity decreased to $2.5 \mathrm{~mA}$. Rats which did not respond consistently within five sessions under the initial shock intensity had shock increased to $2.5 \mathrm{~mA}$. In all other cases, each shock intensity remained in effect for a minimum of 15 sessions during the increasing series of shock intensities and 10 sessions when shock intensity decreased. Shock intensity was changed when performance was stable over five consecutive sessions, provided the minimum number of sessions had been completed. The stability criterion was a variation in the hourly shock rate within $\pm 15 \%$ of the mean rate over five consecutive sessions.

\section{RESULTS}

All of the rats learned to avoid, although three albino rats (AA-6, RA-1, and RA-2) and one black rat (RR-1) did not respond consistently until shock intensity 
Table 1

Animals Comprising the Experimental Groups, Their Weight at the Start of the Experiment, and Sex

\begin{tabular}{|c|c|c|c|c|c|c|c|c|c|c|c|}
\hline \multicolumn{6}{|c|}{ Albino Rats } & \multicolumn{6}{|c|}{ Black Rats } \\
\hline \multicolumn{3}{|c|}{ Foster Raised } & \multicolumn{3}{|c|}{ Conspecific Raised } & \multicolumn{3}{|c|}{ Foster Raised } & \multicolumn{3}{|c|}{ Conspecific Raised } \\
\hline $\mathbf{S}$ & Sex & Weight (g) & $\mathbf{S}$ & Sex & Weight (g) & $S$ & Sex & Weight (g) & $S$ & Sex & Weight (g) \\
\hline \multirow{6}{*}{$\begin{array}{l}\text { RA-1 } \\
\text { RA-2 } \\
\text { RA-3 } \\
\text { RA-4 } \\
\text { RA-5 } \\
\text { RA-7 } \\
\text { RA-8 }\end{array}$} & \multirow{6}{*}{$\begin{array}{l}\mathbf{M} \\
\mathbf{M} \\
\mathbf{F} \\
\mathbf{M} \\
\mathbf{F} \\
\mathbf{M} \\
\mathbf{F}\end{array}$} & \multirow{6}{*}{$\begin{array}{l}372 \\
368 \\
330 \\
370 \\
240 \\
360 \\
322\end{array}$} & AA-6 & F & 205 & AR-1 & F & 253 & RR-9 & F & 188 \\
\hline & & & AA-9 & $\mathbf{F}$ & 240 & AR-2 & $\mathbf{M}$ & 264 & RR-10 & M & 220 \\
\hline & & & AA-10 & $\mathrm{F}$ & 305 & AR-3 & $\mathrm{F}$ & 207 & RR-12 & $\mathbf{M}$ & 225 \\
\hline & & & AA-11 & $\mathbf{M}$ & 350 & $\mathrm{AR}-4$ & $\mathbf{M}$ & 279 & \multirow{3}{*}{\multicolumn{2}{|c|}{ Group Mean }} & 211.0 \\
\hline & & & \multirow{2}{*}{\multicolumn{2}{|c|}{ Group Mean }} & 275.0 & Grour & & 250.8 & & & \\
\hline & & & & & & & & & & & \\
\hline \multicolumn{2}{|c|}{ Group Mean } & 337.4 & & & & & & & & & \\
\hline
\end{tabular}

increased to $2.5 \mathrm{~mA}$. The rats had stable response and shock rates across shock intensities, as shown in Fig. 1, except for wide variations in response rates for Rats AA-6, RA-4, and AR-3 and variations in shock rates for Rats RA-4, AR-1, and AR-2. Black Rat AR-1 had the most inconsistent and ineffective avoidance.

Because of the consistency in performance across shock intensities, it was believed that comparisons between groups at two shock intensities (3.5 and $5.0 \mathrm{~mA}$ ) would be sufficient. Kruskal-Wallis analyses of variance which tested differences in avoidance between groups showed that the albino rats received significantly fewer shocks than the black rats $(H=10.64, d f=1$, $\mathrm{p}<.01)$. Conspecific-raised albino rats avoided more effectively than conspecific-reared black rats $(H=9.60$, $\mathrm{df}=1, \mathrm{p}<.01$ ), while foster-raised albino rats were
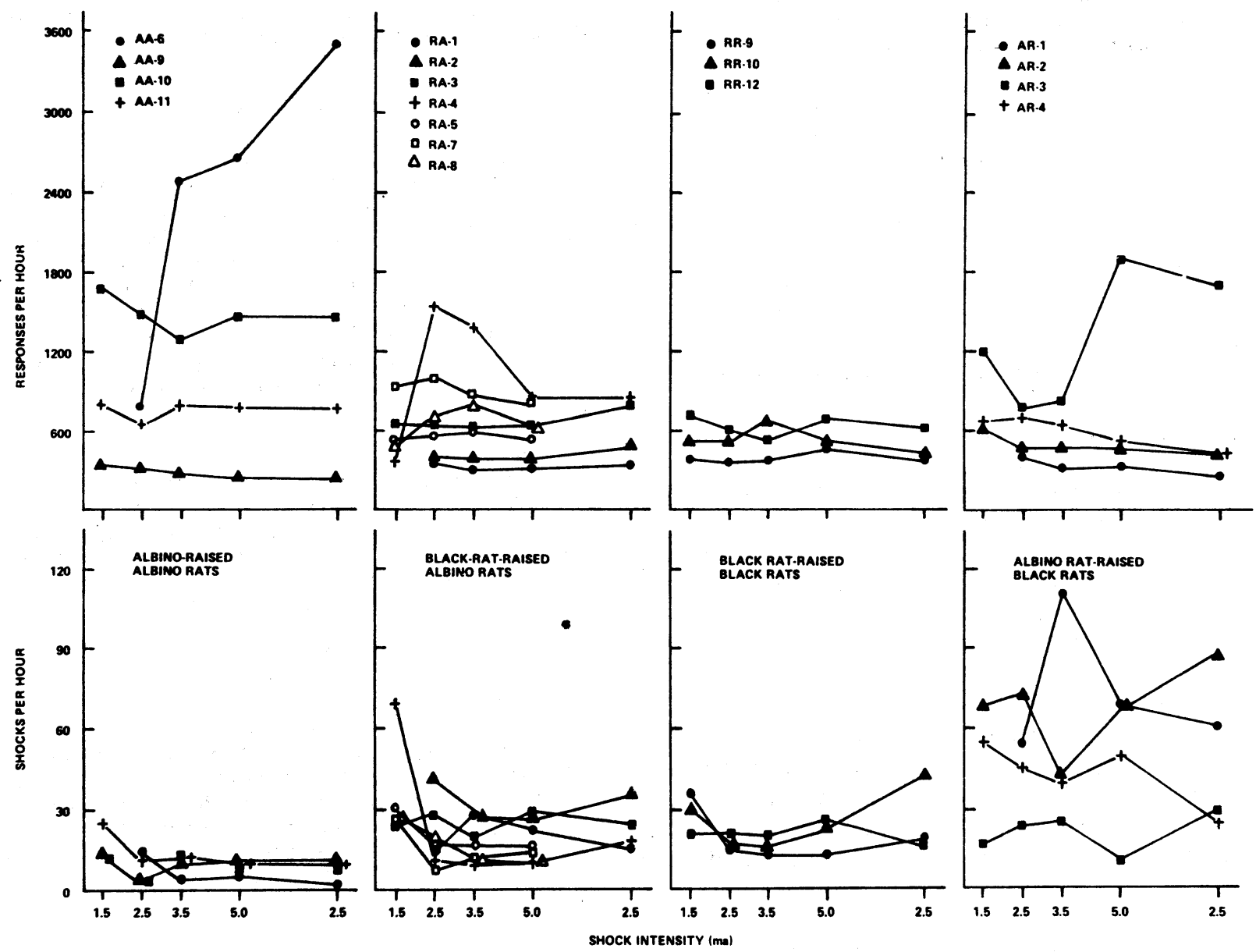

Fig. 1. Mean response and shock rates over the final five sessions at each shock intensity. No data is presented at $1.5 \mathrm{~mA}$ for Rats AA-6, RA-1, RA-2, and RR-1 because performance was below criterion. 
superior to foster-raised black rats $(\mathrm{H}=8.61, \mathrm{df}=1$, $\mathrm{p}<.01)$. As a group, the rats raised by conspecific mothers were superior to the rats raised by foster mothers $(\mathrm{H}=8.06, \mathrm{df}=1, \mathrm{p}<.01)$, with albino rats raised by conspecifics superior to foster-raised albinos $(\mathrm{H}=8.61, \mathrm{df}=1, \mathrm{p}<.01)$, and black rats raised by conspecifics were superior to foster-raised black rats $(H=60.40, \mathrm{df}=1, \mathrm{p}<.05)$. There was no difference in avoidance between sexes for either black rats $(H=.34$, $\mathrm{df}=1, \mathrm{p}<.70)$ or albino rats $(\mathrm{H}=1.26, \mathrm{df}=1$, $\mathrm{p}<.30$ ), nor was there any difference between litters for the black rats $(\mathrm{H}=.26, \mathrm{df}=1, \mathrm{p}<.90)$ or the albino rats $(\mathrm{H}=1.65, \mathrm{df}=1, \mathrm{p}<.20)$.

An analysis of warm-up effects was based upon the final 10 sessions at $3.5-\mathrm{mA}$ shock intensity for each rat. Figure 2 shows that all groups had responses evenly distributed across the first three 20-min intervals of the session. However, the albino rats displayed warm-up, receiving disproportionately large numbers of shocks during the first interval, while the black rats had shocks more uniformly distributed over time. There were only small differences within species between foster-raised and conspecific-raised animals. Kruskal-Wallis analyses showed that the albino rats received a significantly higher percentage of shocks during the first $20 \mathrm{~min}$ of the session than the black rats $(H=8.14, d f=1$, $\mathrm{p}<.01)$. The black rats received a higher percentage of shocks in the second $20 \min (H=5.76, d f=1, p<.02)$, while the difference between species during the third 20-min interval was not significant $(\mathrm{H}=3.28, \mathrm{df}=1$, $\mathrm{p}<.10)$.

\section{DISCUSSION}

The experimental design in this research did not include groups to assess the effects of fostering alone because of the limited number of Ss available. Previous studies which have controlled for intraspecific fostering have reported that this procedure did not influence the amount of parental handling (Ressler, 1962) or later measures of activity emotionality, or social preference in the offspring (Hudgens, Denenberg, \& Zarrow, 1968).

The superior avoidance of the albino rats vs the black rats is consistent with earlier reports. Boice (1970) found albino rats to be markedly superior to wild Norway rats (Rattus norvegicus) in two-way shuttle avoidance. While a recent experiment reported no difference in avoidance shock rates between albino rats and laboratory-raised cotton and black rats, the latter animals required much higher shock intensities than the albino rats to achieve equivalent levels of avoidance (Powell, 1971). In the present study, performance was compared between groups at the same intensity. Also, in comparison with this earlier study, all of the groups in the present experiment avoided more successfully. In fact, five of the black rats in the present experiment avoided as well as the majority of albino rats in the previous study. Also, the black rats showed less variability in performance than they had in the prior experiment. There appear to be two principal reasons for the more successful avoidance of the two species in this experiment: (1) more extended training (approximately $150 \mathrm{~h}$ per rat for the majority of animals here vs a mean of $83 \mathrm{~h}$ per rat in the previous study) and (2) longer experimental sessions ( $2 \mathrm{~h}$ vs $1 \mathrm{~h}$ ), which reduced the influence of warm-up in albino rats upon the overall shock rate, i.e., the rats received substantially fewer shocks in the second hour, so the mean hourly shock rate for the session was lower.
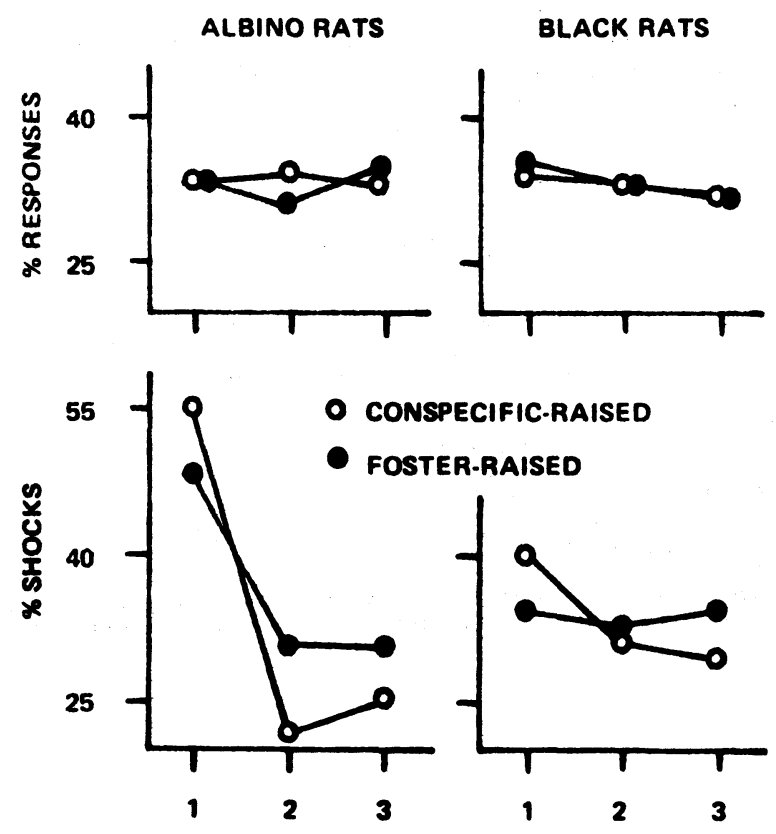

20 MINUTE INTERVALS

Fig. 2. The precentage of responses and shocks for each group during successive 20 -min intervals during the first hour of $2-\mathrm{h}$ sessions.

The present results concur with our previous studies which have reported a relative absence of warm-up during avoidance in nondomesticated rodents (Powell \& Peck, 1969; Powell \& Mantor, 1970; Powell, 1971; Powell, 1972). The amount of warm-up displayed by the foster-raised and conspecific-raised animals of each species was very similar, indicating that the maternal relationship had little influence upon this phenomenon. These results point to the conclusion that warm-up during avoidance is peculiar to domesticated rodents and that it is based upon genetically determined factors, such as emotional reactivity or arousal.

The most surprising result in this experiment was the inferior performance of the foster-raised animals as compared to littermates raised by conspecifics. This suggests that black rat and albino rat mothers behaved differentially toward their foster pups to the extent that performance in a complex learning situation was subsequently impaired. The basis for this impaired performance, such as too much or too little emotional reactivity, and the means by which it developed are matters for further investigation. Previous studies have shown not only that the mother's behavior influences the behavior of the young but also that the offspring's behavior also influences the mother (Ressler, 1962).

One of the important results in this research was the superior avoidance of the black rats in comparison to the earlier experiment (Powell, 1971). The lowest mean hourly shock rate and standard deviation at any shock intensity were as follows: field-raised black rats $(N=4), M=73.5, \quad S D=19.7$; laboratory-raised black rats $(\mathrm{N}=3), \quad \mathrm{M}=55.7, \quad \mathrm{SD}=18.3$ (Powell, 1971, p. 219). The same statistics for the seven black rats studied were: $M=26.4, S D=5.5$. Thus, shock rates were not only substantially lower but also much less variable. In comparison, the lowest hourly shock rate for the albino rats $(N=11)$ here was 11.3 , so the difference between albino and black rats was less than the difference between black rats in the two experiments. As a whole these findings suggest that the life history of the animal and the conditioning procedure to which it 
is exposed are more important as determiners of terminal avoidance behavior than are genotypic differences between closely related species. This is not intended to imply that the latter factors are without influence, for they seem to be implicated in such things as the warm-up effect.

\section{REFERENCES}

Barnett, S. A. The rat. Chicago: Aldine, 1963.

Boice, R. Effect of domestication on avoidance learning in the Norway rat. Psychonomic Science, 1970, 18, 13-14.

Denenberg, V. H., Ottinger, O. R., \& Stephens, M. W. Effects of maternal factors upon growth and behavior of the rat. Child Development, 1962, 33, 65-71.

Hudgens, G. A., Denenberg, V. H., \& Zarrow, M. X. Mice reared with rats: Relations between mother's activity level and offspring's behavior. Journal of Comparative \& Physiological Psychology, 1967, 63, 304-308.

LaBarba, R. C. Emotionality in two strains of mice as a functicn of maternal handling. Psychonomic Science, 1967, 9, 121-122.

Mowrer, O. H., \& Lamoreaux, R. R. Fear as an intervening variable in avoidance conditioning. Journal of Comparative \&
Physiological Psychology, 1946, 39, 29-50.

Powell, R. W. Two-way shuttle avoidance in wild and domesticated mice. Psychonomic Science, 1969, 16, 258-259.

Powell, R. W. Free-operant (Sidman) avoidance in field-raised and laboratory-raised wild rats. Journal of Comparative \& Physiological Psychology, 1971, 75, 216-225.

Powell, R. W. Analysis of warm-up effects during avoidance in wild and domesticated rodents. Journal of Comparative \& Physiological Psychology, 1972, 78, 311-316.

Powell, R. W., \& Mantor, H. Shaping of free-operant avoidance in the wood rat (Neotoma floridana). Psychonomic Science, 1970, 20, 263-265.

Powell, R. W., \& Morris, G. A comparison of escape and avoidance conditioning in wild and domesticated rats. Journal of the Experimental Analysis of Behavior, 1968, 11, 473-478.

Powell, R. W., \& Peck, S. Activity and avoidance in the Mongolian gerbil. Journal of the Experimental Analysis of Behavior, 1969, 12, 779-787.

Ressler, R. H. Parental handling in two strains of mice reared by foster parents. Science, 1962, 137, 129-130.

Sidman, $M$. Two temporal parameters of the maintenance of avoidance behavior by the white rat. Journal of Comparative \& Physiological Psychology, 1953, 46, 253-261.

(Received for publication October 16, 1972.) 